\title{
Relating Plant Biodiversity in Forests with the Spatial Scale of Ecosystem Processes
}

\begin{abstract}
Martin Jenssen
Ecosystem Analysis Department, Institute for Forest Science Eberswalde, Hohensaatener Dorfstraße 27, 16259 Bad Freienwalde, Germany

Correspondence should be addressed to Martin Jenssen, jenssen@waldkunde-eberswalde.de

Received 17 April 2009; Revised 23 August 2009; Accepted 3 December 2009

Recommended by Mark S. Ashton

Plant species diversity of North-Central European forests is quantified by diversity profiles that give different weights to rare and dominant species. Diversity profiles saturate with increasing sample area obeying a hyperbolic saturation model. The paper addresses the question about (1) the spatial scale where this saturation is approached and (2) the nature of related processes. The study is based on about 1,700 vegetation relevés in close-to-nature beech forests and in secondary Scots pine forests which were classified in seven ecosystem types that are distinguished with respect to site factors, dominant tree species, and ecosystem processes. The relevés corresponding to a certain type are successively accumulated to composed relevés with increasing sample area in order to study saturation behaviour. The more weight is given to rare species the larger is the sample area where saturation is approached. The complexity of the processes that determine saturation increases with increasing weight of rare species. With increasing resource availability the part of the occurring plants that have immediate control on local ecosystem processes like primary production, nutrient cycling, and water balance increases. The presented approach allows an estimation of minimum area required for covering vegetation patterns that are related to these processes.
\end{abstract}

Copyright ( $(2009$ Martin Jenssen. This is an open access article distributed under the Creative Commons Attribution License, which permits unrestricted use, distribution, and reproduction in any medium, provided the original work is properly cited.

\section{Introduction}

Biological diversity is a complex phenomenon and it is hard to reduce this phenomenon to only one measure. Instead, various measures could be useful in order to characterize different properties of species distributions and community structure $[1,2]$. Some authors use diversity profiles derived from one-parameter functions comprising species richness, Shannon and Simpson indices as special cases [3-6]. These diversity profiles can be used to study the effect of relative species abundance on diversity.

According to Grime's "mass-ratio" theory [7], dominant and subordinate species have immediate control on ecosystem processes like nutrient cycling and water balance due to their overwhelming contribution to primary production. On the other hand, Grime emphasizes the importance of occasional or transient species for ecosystem function and sustainability. These low-abundant species originate from the seed dispersal and seed banks and provide the potential for developing new dominants and subordinates following temporal perturbations or systematic shifts of site conditions as can be expected, for example, in the outcome of climate change. The effects of these species become apparent on longer time scales.

Grime's theory provides a linkage between species abundance, species function in the ecosystem, corresponding ecosystem processes and the temporal scale of these processes. In this paper I suggest a linkage between species abundance, diversity patterns, and the spatial scale of corresponding ecosystem processes.

The diversity profiles are derived from the following one parameter function with $p_{i}$ denoting relative species abundances:

$$
H=\frac{1}{1-q} \ln \left(\sum_{i=1}^{s} p_{i}^{q}\right)
$$

This function is a generalized expression for an information entropy as described by Rényi [8]. The Rényi entropies of a given species distribution are weakly decreasing functions 
TABLE 1: Ecological key parameters for an ecological series of close-to-nature European beech (Fagus sylvatica) forest ecosystem types of the Northern Central Europe compared to secondary Scots pine (Pinus sylvestris) forest ecosystem types which substitute beech forest on large parts of the woodlands mainly in the Eastern lowland regions [23].

\begin{tabular}{|c|c|c|c|c|}
\hline \multirow{3}{*}{ Parameter } & \multicolumn{4}{|c|}{ Close-to-nature European beech forest ecosystem types } \\
\hline & 1 & 2 & 3 & 4 \\
\hline & $\begin{array}{l}\text { Mercuriali- } \\
\text { Fagetum } \\
\text { sylvaticae }\end{array}$ & $\begin{array}{c}\text { Melico-Fagetum } \\
\text { sylvaticae }\end{array}$ & $\begin{array}{l}\text { Milio-Fagetum } \\
\text { sylvaticae }\end{array}$ & $\begin{array}{c}\text { Majanthemo- } \\
\text { Fagetum } \\
\text { sylvaticae }\end{array}$ \\
\hline Soil substrate & marl, marly loam & loam & $\begin{array}{l}\text { sandy loam, loamy } \\
\text { sand }\end{array}$ & sand \\
\hline $\begin{array}{l}\text { Soil nutrient } \\
\text { status }\end{array}$ & $\begin{array}{l}\text { hypertrophic, } \\
\text { carbonate }\end{array}$ & eutrophic & meso- to eutrophic & $\begin{array}{l}\text { mesotrophic, } \\
\text { meso- to } \\
\text { oligotrophic }\end{array}$ \\
\hline Humus type & mull & mull-like moder & $\begin{array}{l}\text { mull-like moder to } \\
\text { moder }\end{array}$ & moder \\
\hline $\mathrm{C} / \mathrm{N}(0-5 \mathrm{~cm})$ & $10-12$ & $13-15$ & $16-18$ & $19-22$ \\
\hline Site index $(\mathrm{m})$ & $32.7 \pm 1.8$ & $30.6 \pm 2.6$ & $28.3 \pm 2.6$ & $25.4 \pm 2.6$ \\
\hline \multirow[t]{2}{*}{$\begin{array}{l}\text { Ecosystem } \\
\text { productivity }^{\mathrm{b}} \\
(\mathrm{t} / \mathrm{ha})\end{array}$} & $11.6 \pm 0.9$ & $10.8 \pm 1.2$ & $9.5 \pm 1.1$ & $7.6 \pm 1.0$ \\
\hline & \multicolumn{4}{|c|}{ Secondary Scots pine forest ecosystem types } \\
\hline \multirow[t]{2}{*}{ Parameter } & & $2^{\prime}$ & $3^{\prime}$ & $4^{\prime}$ \\
\hline & & $\begin{array}{c}\text { Rubo-Culto- } \\
\text { Pinetum } \\
\text { sylvestris }\end{array}$ & $\begin{array}{l}\text { Rubo-Avenello- } \\
\text { Culto-Pin.sylv. }\end{array}$ & $\begin{array}{c}\text { Avenello-Culto- } \\
\text { Pinetum } \\
\text { sylvestris }\end{array}$ \\
\hline Soil substrate & & loam & $\begin{array}{l}\text { sandy loam, loamy } \\
\text { sand }\end{array}$ & sand \\
\hline $\begin{array}{l}\text { Soil nutrient } \\
\text { status }\end{array}$ & & eutrophic & meso- to eutrophic & $\begin{array}{l}\text { meso- to } \\
\text { oligotrophic }\end{array}$ \\
\hline Humus type & & moder & $\begin{array}{l}\text { raw humus-like } \\
\text { moder }\end{array}$ & raw humus \\
\hline $\mathrm{C} / \mathrm{N}(0-5 \mathrm{~cm})$ & & $20-22$ & $23-25$ & $27-29$ \\
\hline Site index $(\mathrm{m})$ & & $28.0 \pm 1.8$ & $27.3 \pm 1.7$ & $21.3 \pm 3.6$ \\
\hline $\begin{array}{l}\text { Ecosystem } \\
\text { productivity } \\
\text { (t/ha) }\end{array}$ & & $8.3 \pm 0.6$ & $7.8 \pm 0.6$ & $6.2 \pm 1.1$ \\
\hline
\end{tabular}

${ }^{a}$ Mean basal area height of trees at 100 years.

${ }^{\mathrm{b}}$ Maximum average net primary production of aboveground biomass (dry weight).

of the parameter $q$. As $q$ approaches the limit one, it can be shown that

$$
\lim _{q \rightarrow 1} H=-\sum_{i=1}^{S} p_{i} \ln p_{i}
$$

yields the well-known Shannon information entropy [811]. Shannon diversity mainly stresses medium abundances (relative abundances of the order $1 / e$ ), whereas very small or very large $p_{i}$ provide only minor contributions to this measure.

Generalized information entropy or Rényi diversity due to (1) corresponds to a so-called "escort distribution" $p^{q}$ that weights species of different relative abundance depending on the parameter $q[12]$. Hill [3] proposed the use of the exponential function of Rényi diversity according to (1), which he calls moments of the species distribution:

$$
M=e^{H} .
$$

These moments characterize different properties of the species distribution. Lower moments $(q<1)$ give greater weight to rare species. For $q=0$ each species makes the same contribution to diversity and (3) yields species richness represented by species number

$$
M=S
$$

Higher moments $(q>1)$ give greater weight to more abundant species. Equations (1) and (3) yield with $q=2$

$$
M=\frac{1}{\sum_{i=1}^{S} p_{i}^{2}},
$$


TABLE 2: Average percent cover of plant species (sum of cover percents $\sum_{n=1}^{N} D$ divided by the number of relevés $N$ ) in four widespread beech (Fagus sylvatica) forest ecosystem types of the North-Central European lowlands (Table 1). Percent covers below 1\% are not considered.

European beech forest ecosystem type

Species $\quad 1 \quad 2 \quad 3 \quad 4$

Mercuriali-Fagetum sylv. Melico-Fagetum sylv. Milio-Fagetum sylv. Majanthemo-Fagetum sylvaticae

Tree layer

Acer pseudoplatanus 3

Fraxinus excelsior 2

Tilia cordata 2

Ulmus glabra 1

Carpinus betulus 3

Fagus sylvatica $\quad 67$

Quercus petraea 1

Quercus robur $\quad 1$

Pinus sylvestris

\begin{tabular}{|c|c|c|c|c|}
\hline \multicolumn{5}{|l|}{ Shrub layer } \\
\hline Sambucus nigra & 2 & & & \\
\hline Acer campestre & 1 & & & \\
\hline Fraxinus excelsior & 1 & & & \\
\hline Rubus idaeus & 1 & 1 & 1 & \\
\hline Fagus sylvatica & 3 & 3 & 3 & 9 \\
\hline
\end{tabular}

Herb layer

Mercurialis perennis $\quad 25$

Aegopodium podagraria $\quad 8$

Anemone ranunculoides 3

Sanicula europea 2

Impatiens parviflora 2

Glechoma hederacea 1

Impatiens noli-tangere $\quad 1$

Dryopteris filix-mas 1

Corydalis cava 1

Circaea lutetiana 1

Geranium robertianum 1

Geum urbanum 1

Stachys sylvatica $\quad 1$

Elymus caninus 1

Pulmonaria obscura $\quad 1$

Hordelymus europaeus $\quad 1$

Hepatica nobilis $\quad 1$

Dentaria bulbifera 1

Polygonatum multiflorum 1

Melica uniflora $\quad 8$

Lamium galeobdolon $\quad 11$

Ranunculus ficaria $\quad 13$

Urtica dioica 2

Deschampsia cespitosa

Festuca gigantea $\quad 1$

Stellaria holostea 2

Carex sylvatica

Milium effusum

Galium odoratum

Brachypodium sylvaticum

Dactylis polygama

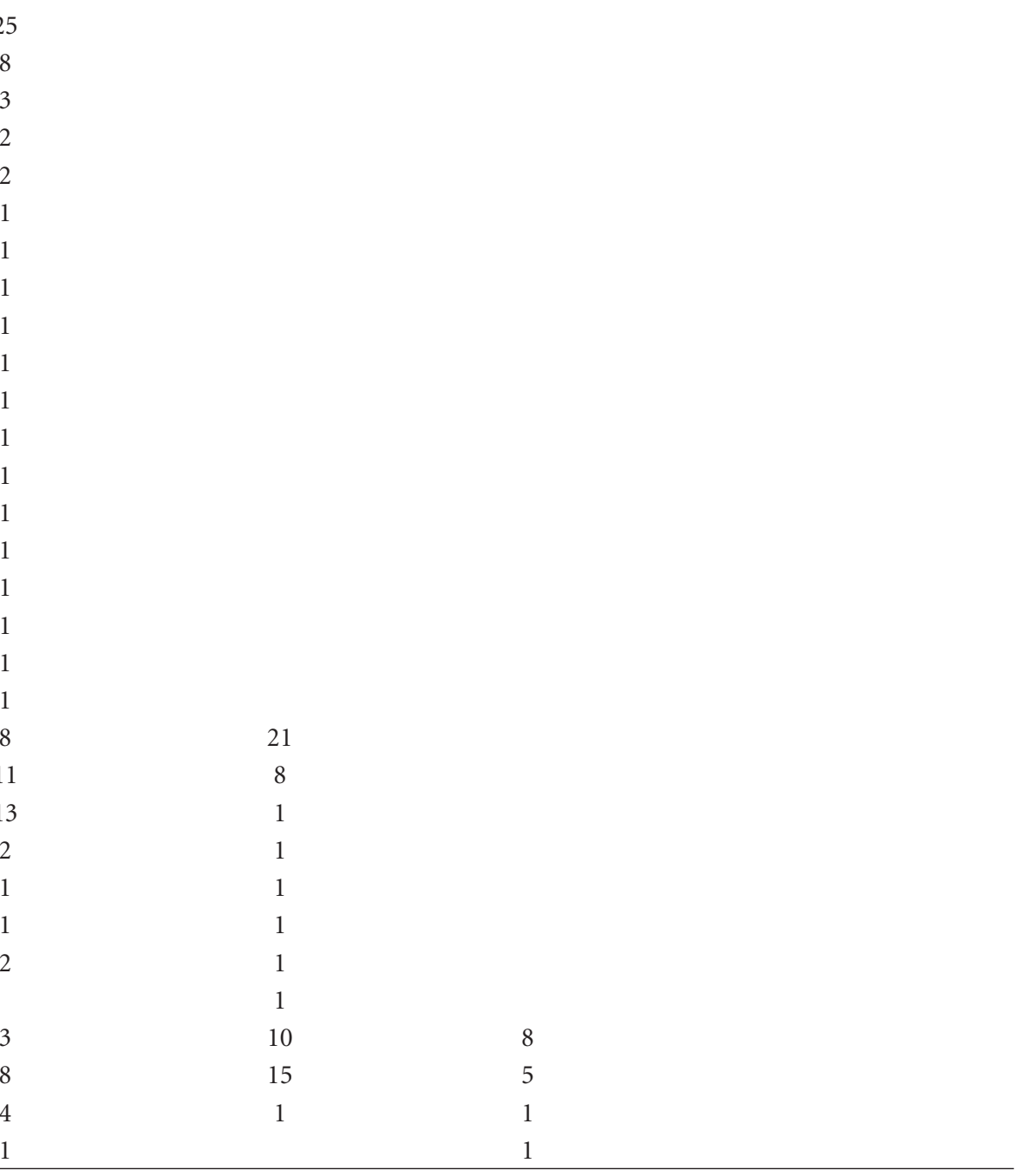

1

$\begin{array}{lll}82 & 82 & 69\end{array}$

2

$1+6$

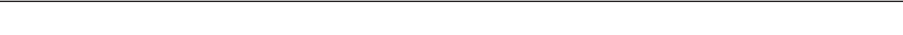


Table 2: Continued.

\begin{tabular}{|c|c|c|c|c|}
\hline \multirow{3}{*}{ Species } & \multicolumn{4}{|c|}{ European beech forest ecosystem type } \\
\hline & 1 & 2 & 3 & 4 \\
\hline & Mercuriali-Fagetum sylv. & Melico-Fagetum sylv. & Milio-Fagetum sylv. & Majanthemo-Fagetum sylvaticae \\
\hline Viola reichenbachiana & & 1 & 1 & \\
\hline Festuca heterophylla & & & 4 & \\
\hline Anemone nemorosa & 9 & 16 & 10 & 1 \\
\hline Oxalis acetosella & 6 & 11 & 9 & 1 \\
\hline Poa nemoralis & & 1 & 4 & 1 \\
\hline Carex pilulifera & & & 1 & 1 \\
\hline Maianthemum bifolium & & & 1 & 2 \\
\hline Convallaria maialis & & & & 2 \\
\hline Deschampsia flexuosa & & & & 2 \\
\hline Calamagrostis epigeios & & & & 2 \\
\hline \multicolumn{5}{|l|}{ Moss layer } \\
\hline Atrichum undulatum & & 1 & & \\
\hline Polytrichum formosum & & & & 1 \\
\hline
\end{tabular}

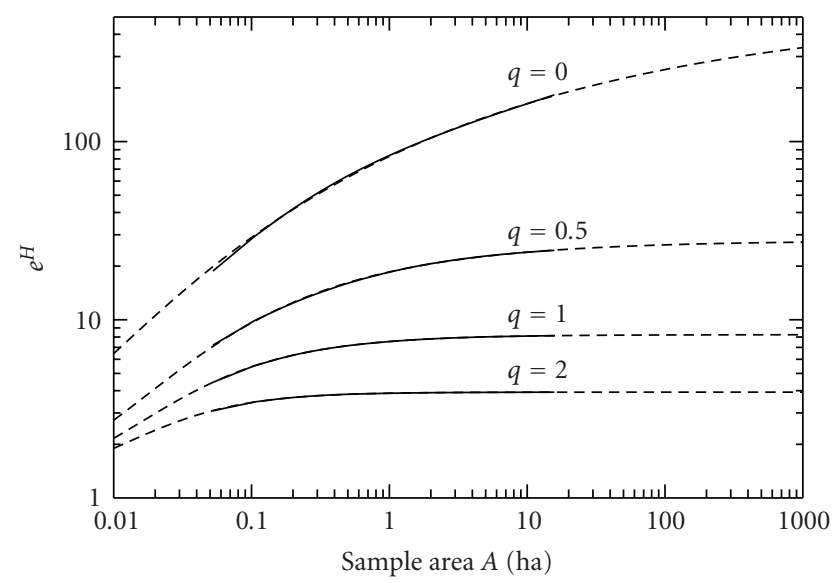

Figure 1: Moments of Rényi diversities $\exp (H)$ plotted versus sample area $A$ for North-Central European beech forests on eutrophic loam soils (Melico Fagetum). The moments of order $q=$ 0 equal species number $S$, the curve $q=1$ corresponds to the Shannon diversity index, and the curve $q=2$ is related to Simpson diversity index. The full lines correspond to the curve sections that were calculated from the data material. The dashed sections of the curves were modelled according to (9) using the parameters listed in Table 3.

which is related to the well-known Simpson index [13]. If the probabilities $p_{i}$ are the same, then all the moments of Rényi diversities equal the species number $S$ which proves to be the upper limit of (3). The moments can be interpreted as an effective or apparent species number representing the minimum number of species of equal abundance required to produce the same diversity value $[14,15]$.

Equations (1) and (3) can be used to plot continuous diversity profiles, that is, to plot the diversities $H$ or the moments $M$ versus the parameter $q$. These diversity profiles allow a comprehensive ecological interpretation [3-5]. Any deviation from complete evenness of species distribution

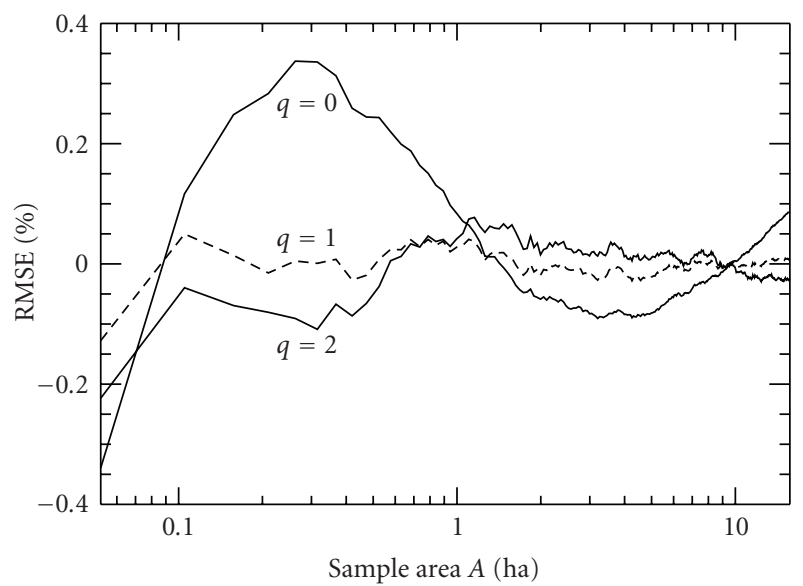

FIGURE 2: Root mean squared error in percentage (RMSE\%) of Rényi diversities $H$ plotted versus sample area $A$ for the species diversity model of ecosystem type Melico Fagetum (Figure 1) according to (9) using the parameters listed in Table 3. The full line corresponds to moments of order $q=0$ (species number), the dashed line to $q=1$ (Shannon diversity), and the dotted line to $q=2$ (Simpson diversity).

yields a monotonically decreasing diversity profile with increasing $q$. The more rapidly the profile declines, the lower the evenness of the system. Diversity profiles of different samples may be comparable; that is, they do not intersect over the entire range of $q$. In this case one sample can be said to be more diverse than the other one. But even intersecting curves give rise to an ecological interpretation if we understand the ecological processes that determine different moments of the distributions. In this way diversity profiles might be very helpful for the investigation of relationships between diversity and ecological processes. 
TABle 3: Parameters of the hyperbolic saturation model (9) and error measures for the close-to-nature European beech (Fagus sylvatica) forests types (1-4) with ecological site factors according to Table 1.

\begin{tabular}{|c|c|c|c|c|}
\hline Ecosystem type 1 & \multicolumn{4}{|c|}{ Mercuriali-Fagetum sylvaticae } \\
\hline Number of relevés $\mathrm{N}$ & \multicolumn{4}{|c|}{244} \\
\hline Mean sample area of relevés & \multicolumn{4}{|c|}{0.07 ha } \\
\hline $\begin{array}{l}\text { Mean species number of relevés } \\
( \pm \text { standard deviation })\end{array}$ & \multicolumn{4}{|c|}{$33 \pm 11$} \\
\hline Median of species number & \multicolumn{4}{|c|}{33} \\
\hline Mode* of species number & \multicolumn{4}{|c|}{33} \\
\hline Parameter $q$ & 0 & 0.5 & 1 & 2 \\
\hline$H_{S}$ & 6.52 & 4.09 & 2.95 & 1.86 \\
\hline$\alpha[\mathrm{ha}]$ & 0.002 & 0.012 & 0.019 & 0.016 \\
\hline$\kappa$ & 0.21 & 0.50 & 0.73 & 1.05 \\
\hline RMSE & 0.0149 & 0.0019 & 0.0019 & 0.0003 \\
\hline RMSE\% & 0.33 & 0.05 & 0.08 & 0.02 \\
\hline Ecosystem type 2 & \multicolumn{4}{|c|}{ Melico-Fagetum sylvaticae } \\
\hline Number of relevés $\mathrm{N}$ & \multicolumn{4}{|c|}{300} \\
\hline Mean sample area of relevés & \multicolumn{4}{|c|}{0.06 ha } \\
\hline $\begin{array}{l}\text { Mean species number of relevés } \\
( \pm \text { standard deviation })\end{array}$ & \multicolumn{4}{|c|}{$20 \pm 6$} \\
\hline Median of species number & \multicolumn{4}{|c|}{20} \\
\hline Mode* of species number & \multicolumn{4}{|c|}{20} \\
\hline Parameter $q$ & 0 & 0.5 & 1 & 2 \\
\hline$H_{S}$ & 6.33 & 3.33 & 2.11 & 1.37 \\
\hline$\alpha[\mathrm{ha}]$ & 0.002 & 0.008 & 0.011 & 0.012 \\
\hline$\kappa$ & 0.19 & 0.43 & 0.70 & 1.03 \\
\hline RMSE & 0.0072 & 0.0025 & 0.0003 & 0.0004 \\
\hline RMSE\% & 0.17 & 0.09 & 0.01 & 0.03 \\
\hline Ecosystem type 3 & \multicolumn{4}{|c|}{ Milio-Fagetum sylvaticae } \\
\hline Number of relevés $N$ & \multicolumn{4}{|c|}{203} \\
\hline Mean sample area of relevés & \multicolumn{4}{|c|}{0.07 ha } \\
\hline $\begin{array}{l}\text { Mean species number of relevés } \\
( \pm \text { standard deviation })\end{array}$ & \multicolumn{4}{|c|}{$15 \pm 6$} \\
\hline Median of species number & \multicolumn{4}{|c|}{14} \\
\hline Mode* of species number & \multicolumn{4}{|c|}{14} \\
\hline Parameter $q$ & 0 & 0.5 & 1 & 2 \\
\hline$H_{S}$ & 5.60 & 3.34 & 1.88 & 0.98 \\
\hline$\alpha[$ ha $]$ & 0.009 & 0.025 & 0.025 & 0.024 \\
\hline$\kappa$ & 0.30 & 0.46 & 0.65 & 1.21 \\
\hline RMSE & 0.0098 & 0.0046 & 0.0020 & 0.0020 \\
\hline RMSE $\%$ & 0.22 & 0.22 & 0.15 & 0.15 \\
\hline Ecosystem type 4 & \multicolumn{4}{|c|}{ Majanthemo-Fagetum sylvaticae } \\
\hline Number of relevés $\mathrm{N}$ & \multicolumn{4}{|c|}{158} \\
\hline Mean sample area of relevés & \multicolumn{4}{|c|}{0.10 ha } \\
\hline $\begin{array}{l}\text { Mean species number of relevés } \\
( \pm \text { standard deviation })\end{array}$ & \multicolumn{4}{|c|}{$12 \pm 5$} \\
\hline Median of species number & \multicolumn{4}{|c|}{11} \\
\hline Mode* of species number & & 10 & & \\
\hline Parameter $q$ & 0 & 0.5 & 1 & 2 \\
\hline$H_{S}$ & 5.58 & 3.02 & 1.36 & 0.55 \\
\hline$\alpha[\mathrm{ha}]$ & 0.019 & 0.065 & 0.052 & 0.031 \\
\hline$\kappa$ & 0.29 & 0.46 & 0.57 & 1.06 \\
\hline RMSE & 0.0020 & 0.0058 & 0.0028 & 0.0004 \\
\hline RMSE\% & 0.06 & 0.37 & 0.32 & 0.08 \\
\hline
\end{tabular}

* Calculated from a Gaussian fitting. 
TABle 4: Parameters of the hyperbolic saturation model (9) and error measures for the secondary Scots pine (Pinus sylvestris) forest types $\left(2^{\prime}-4^{\prime}\right)$ substituting European beech (Fagus sylvatica) forests types (2-4).

\begin{tabular}{|c|c|c|c|c|}
\hline Ecosystem type $2^{\prime}$ & & Rubo & sylvestris & \\
\hline Number of relevés $N$ & & 70 & & \\
\hline Mean sample area of relevés & & 0.08 ha & & \\
\hline $\begin{array}{l}\text { Mean species number of relevés } \\
\text { ( } \pm \text { standard deviation })\end{array}$ & & $28 \pm 8$ & & \\
\hline Median of species number & & 26 & & \\
\hline Mode* of species number & & 26 & & \\
\hline Parameter $q$ & 0 & 0.5 & 1 & 2 \\
\hline$H_{S}$ & 6.75 & 4.16 & 2.92 & 2.02 \\
\hline$\alpha[$ ha $]$ & 0.004 & 0.011 & 0.017 & 0.023 \\
\hline$\kappa$ & 0.22 & 0.42 & 0.67 & 1.10 \\
\hline RMSE & 0.0010 & 0.0017 & 0.0013 & 0.0004 \\
\hline RMSE\% & 0.03 & 0.05 & 0.05 & 0.02 \\
\hline Ecosystem type $3^{\prime}$ & & Rubo-Aver & tum sylve. & \\
\hline Number of relevés $N$ & & 286 & & \\
\hline Mean sample area of relevés & & 0.06 ha & & \\
\hline $\begin{array}{l}\text { Mean species number of relevés } \\
( \pm \text { standard deviation })\end{array}$ & & $21 \pm 5$ & & \\
\hline Median of species number & & 21 & & \\
\hline Mode* of species number & & 21 & & \\
\hline Parameter $q$ & 0 & 0.5 & 1 & 2 \\
\hline$H_{S}$ & 7.21 & 3.82 & 2.53 & 1.77 \\
\hline$\alpha$ [ha] & 0.002 & 0.007 & 0.012 & 0.014 \\
\hline$\kappa$ & 0.17 & 0.37 & 0.65 & 1.04 \\
\hline RMSE & 0.0036 & 0.0006 & 0.0008 & 0.0007 \\
\hline RMSE $\%$ & 0.08 & 0.02 & 0.04 & 0.04 \\
\hline Ecosystem type $4^{\prime}$ & & Avenell & i sylvestri & \\
\hline Number of relevés $N$ & & 411 & & \\
\hline Mean sample area of relevés & & 0.06 ha & & \\
\hline $\begin{array}{l}\text { Mean species number of relevés } \\
( \pm \text { standard deviation })\end{array}$ & & $16 \pm 6$ & & \\
\hline Median of species number & & 15 & & \\
\hline Mode* of species number & & 14 & & \\
\hline Parameter $q$ & 0 & 0.5 & 1 & 2 \\
\hline$H_{s}$ & 7.73 & 3.27 & 1.90 & 1.36 \\
\hline$\alpha[$ ha $]$ & 0.002 & 0.006 & 0.009 & 0.013 \\
\hline$\kappa$ & 0.13 & 0.32 & 0.62 & 1.07 \\
\hline RMSE & 0.0042 & 0.0011 & 0.0006 & 0.0003 \\
\hline RMSE\% & 0.13 & 0.05 & 0.03 & 0.02 \\
\hline
\end{tabular}

* Calculated from a Gaussian fitting.

Diversity profiles saturate with increasing sample area. In previous work it was shown that Shannon diversity according to (2) obeys the ordinary differential equation [16]:
Equation (6) with $k>1$ defines a hyperbolic saturation model approaching a finite value on infinite sample area $A$ $[17,18]$. The saturation diversities can be obtained easily:

$$
\frac{d H}{d A}=C \cdot\left(H_{S}-H\right)^{k}
$$

$$
\lim H(A)_{A \rightarrow \infty}=H_{S} .
$$




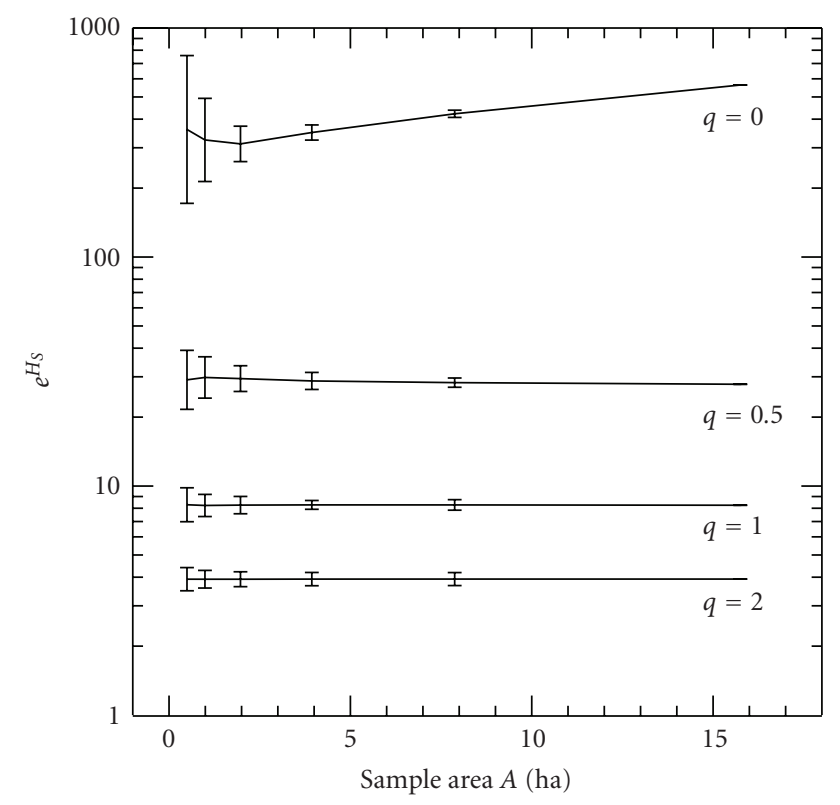

Figure 3: Moments of saturation diversities $\exp \left(H_{S}\right)$ for NorthCentral European beech forests on eutrophic loam soils (Melico Fagetum) predicted by the model (9) from samples of different sample area $A$. The error bars represent the standard deviations obtained from each $16,8,6,4$, and 2 independent samples of the respective sample area $A$.

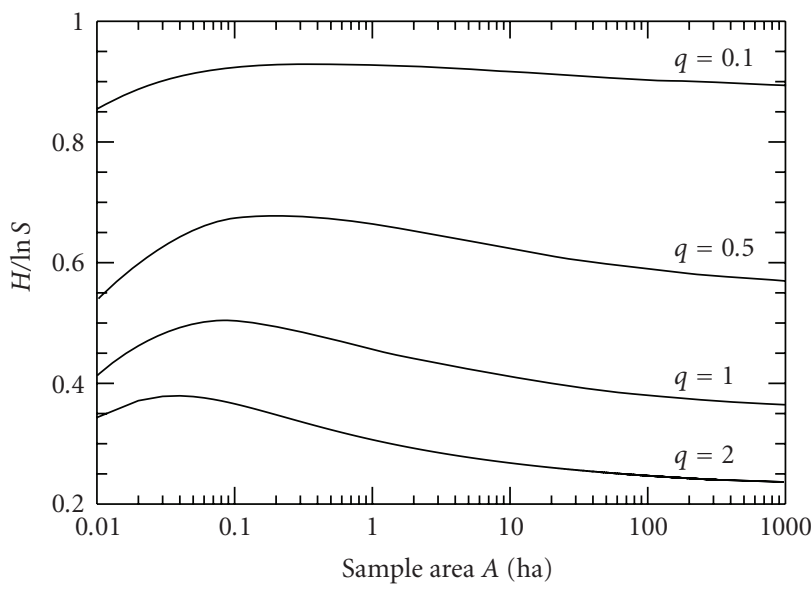

FIGURE 4: Evenness measures of plant species distribution $H / \ln S$ with different values of the parameter $q$ versus the area $A$ for the ecosystem type Melico Fagetum. The curve for $q=1$ corresponds to the well-known Shannon evenness.

Accumulating samples with similar ecological constraints yields a saturation diversity $H_{S}$ that represents the corresponding ecosystem type. This saturation diversity corresponds to a species distribution that reflects the diversity potential of a site with the given ecological constraints [16].

In the following I will demonstrate that (6) holds for the saturation of diversity profiles in a wide range of the parameter $q$. The equation will be used for deriving characteristic spatial scales of diversity patterns for different branches of diversity profiles, that is, for dominant, subordinate, and rare

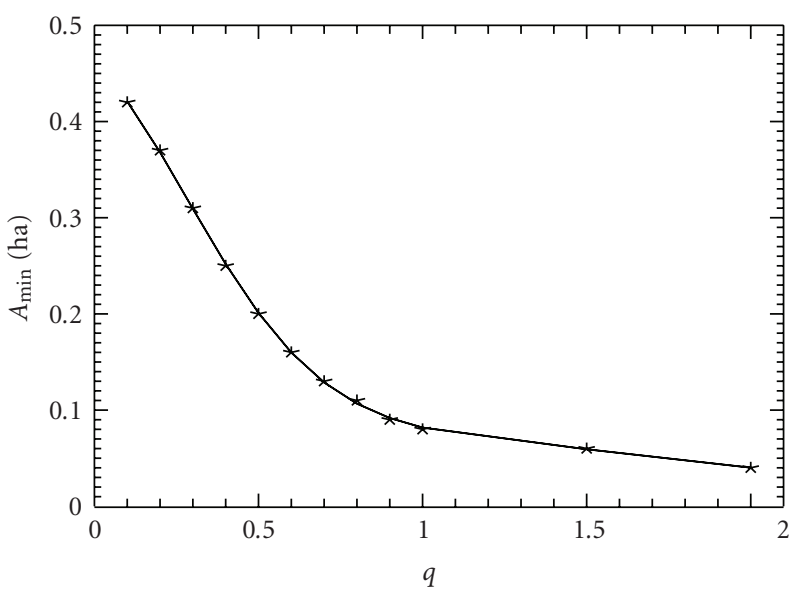

Figure 5: Area $A_{\min }$ where evenness $E=H / \ln S$ (see (10) and Figure 4) approaches its maximum $E\left(A_{\min }\right)=\max (E)$ versus $q$ for the ecosystem type Melico Fagetum. $A_{\min }$ represents the minimum area for surveying all the species that provide major contributions to the saturation diversities of order $q$.

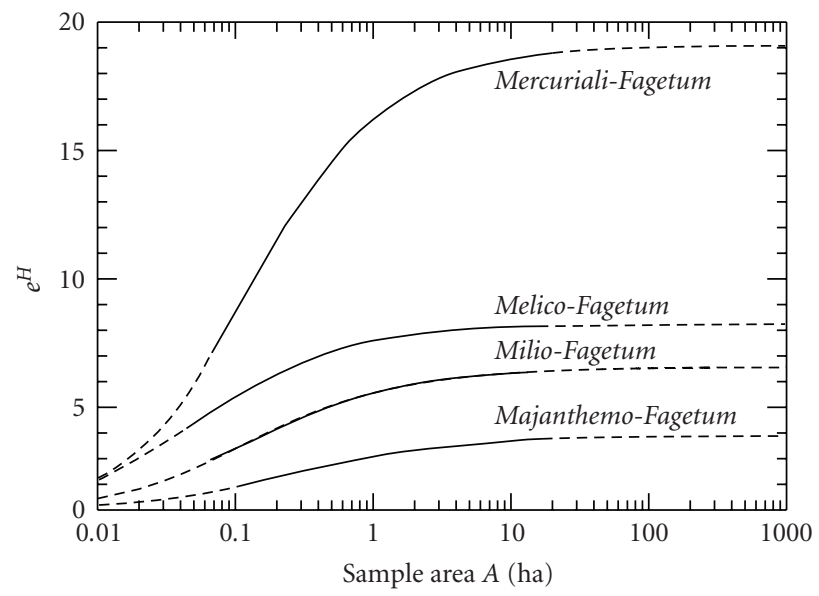

Figure 6: Moment of Shannon diversity $\exp (H)$ (effective species number) plotted versus sample area $A$ for the ecological series of North-Central European beech forests according to Tables 1 and 2 . The full lines correspond to the curve sections that were calculated from the data material. The dashed sections of the curves were modelled according to (9) using the parameters listed in Table 3.

species which have different meaning for ecosystem function according to Grime's theory.

Furthermore, (6) will be used to estimate the complexity of the ecosystem processes that are related to different branches of diversity profiles. The exponent $k>1$ in (6) characterizes the hyperbolic asymptotic approximation to the saturation value of diversity which is forced by the ecological constraints mainly given by species pool and resource availability. Mende proposed that this exponent plays the role of a complexity measure [17]. This proposal was confirmed by the investigation of many natural and social growth and saturation processes which are highly cooperative [17-20]. The more $k$ deviates from one, the larger are the number and the networking of the different 


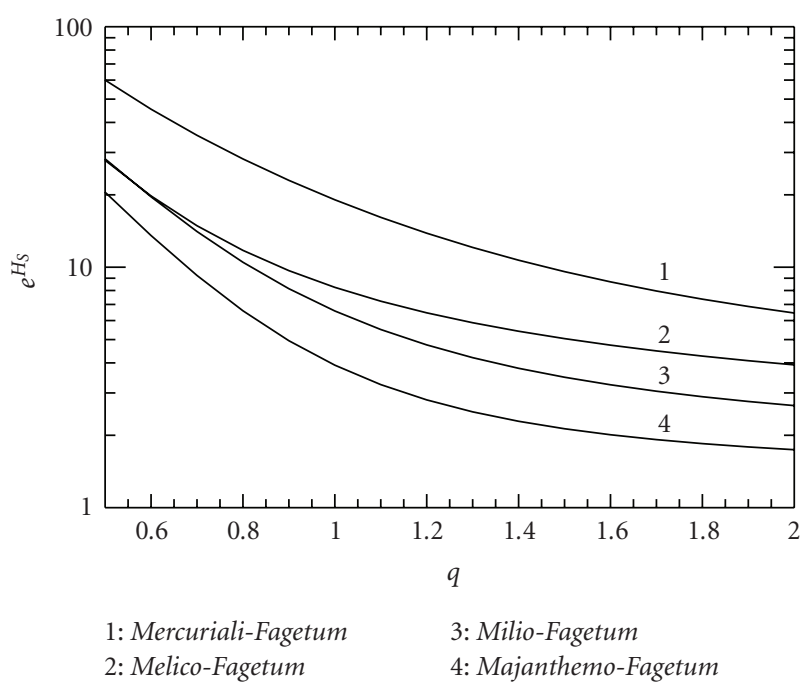

FIGURE 7: Diversity profiles (saturation entropies $\exp \left(H_{S}\right)$ versus $q$ ) for the ecological series of North-Central European beech forests according to Tables 1 and 2. Saturation diversities were modelled according to (9) using the parameters listed in Table 3.

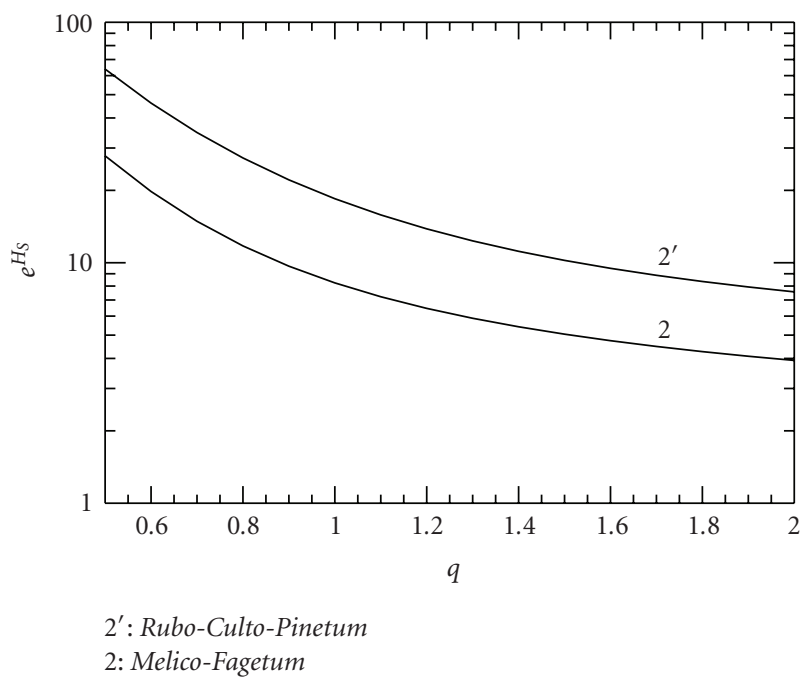

Figure 8: Diversity profile (saturation diversities $\exp \left(H_{S}\right)$ versus q) for close-to-nature beech forests (Melico Fagetum) compared to the diversity profile of secondary Scots pine forests (Rubo-CultoPinetum) on eu- to mesotrophic loam soils (Table 1). Saturation diversities were modelled according to (9) using the parameters listed in Tables 3 and 4.

processes that determine saturation. In this way I intend to relate diversity patterns with the spatial scale and complexity of ecosystem processes.

\section{Material and Methods}

Profiles of saturation diversity (i.e., $H_{S}$ according to (1) and (7) versus $q$ ) were calculated for a series of widespread European beech (Fagus sylvatica L.) forests within Northern Central Europe. These forests correspond to the potential

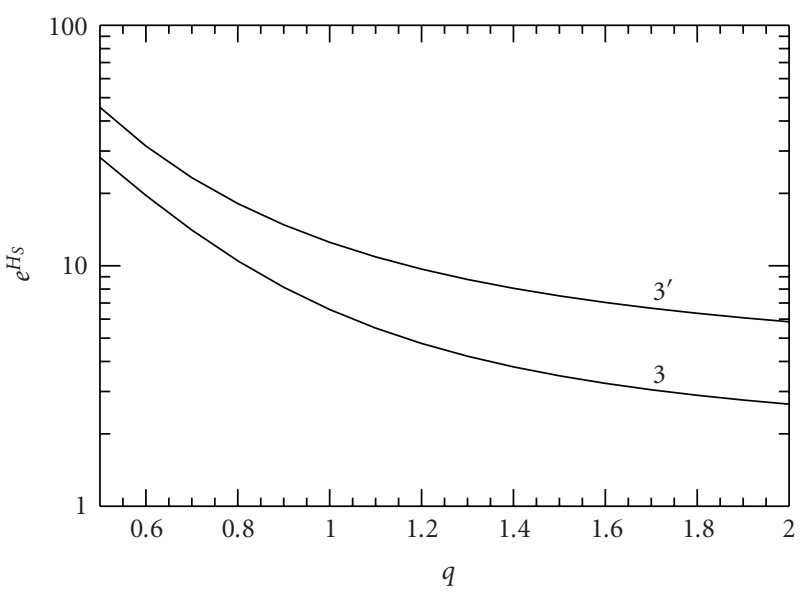

$3^{\prime}$ : Rubo-Avenello-Culto-Pinetum

3: Milio-Fagetum

FIGURE 9: Diversity profile (saturation diversities $\exp \left(H_{S}\right)$ versus q) for close-to-nature beech forests (Milio Fagetum) compared to the diversity profile of secondary Scots pine forests (Rubo-AvenelloCulto-Pinetum) on meso- to eutrophic loamy sand soils (Table 1). Saturation entropies were modelled according to (9) using the parameters listed in Tables 3 and 4 .

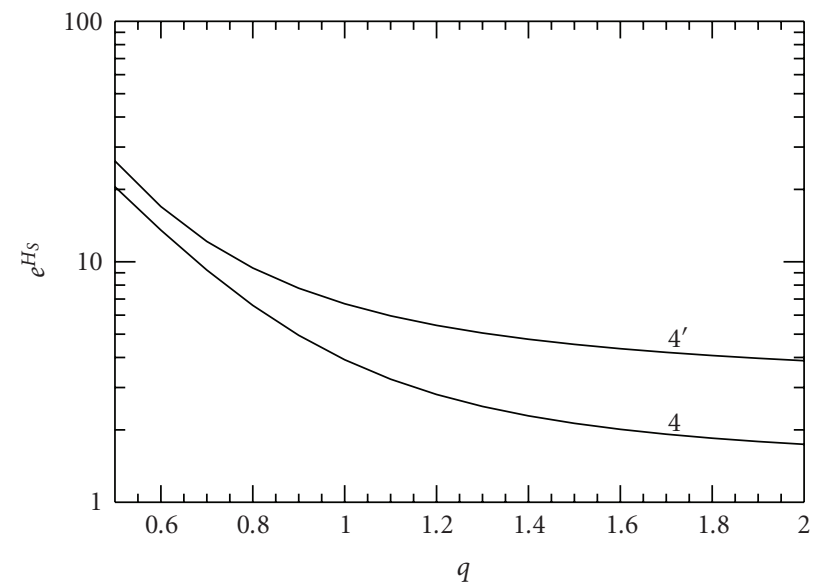

$4^{\prime}$ : Avenello-Culto-Pinetum

4: Majanthemo-Fagetum

FIGURE 10: Diversity profile (saturation diversities $\exp \left(H_{S}\right)$ versus $q$ ) for close-to-nature beech forests (Majanthemo Fagetum) compared to the diversity profile of secondary Scots pine forests (AvenelloCulto-Pinetum) on meso- to oligotrophic sand soils (Table 1). Saturation entropies were modelled according to (9) using the parameters listed in Table 3 .

natural vegetation in regions with suboceanic climates where the soils are not affected by ground- or backwater [21, 22]. The different beech forest types are distinguished by soil substrate and nutrient status (Table 1). For comparison, a series of secondary Scots pine (Pinus sylvestris L.) forests was investigated. The latter coniferous forests replace the beech forests in the overwhelming number of forest sites in the East German lowlands comprising the German Federal 
States of Mecklenburg-Western-Pomerania, the northern part of Brandenburg, and parts of Saxony and SaxonyAnhalt. Altogether, 905 vegetation relevés in mature closeto-nature beech forests and 767 relevés in mature secondary Scots pine forests (recorded between 1950 and 2006) were analysed for the present study.

The individual sample plot area varied between 400 and $1600 \mathrm{~m}^{2}$. The species occurring of soil-covering vascular plants, mosses, and lichens were encountered within these sample plots. The percentage cover of plant species was estimated on the scale $r$ (very little coverage, very few individuals), + (little coverage, few individuals), $1 \%$ up to $10 \%$ in $1 \%$ increment steps, $10 \%$ up to $100 \%$ in $5 \%$ increment steps. For calculation purposes, $r$ was set equal $0.01 \%$ and + was set equal $0.2 \%$.

The vegetation relevés were classified into four beech forest types and three Scots pine forest types due the principles developed by Hofmann [24]. According to these principles, vegetation is typified considering not only presence or absence but also percentage cover of species or species groups as well. It was shown that these vegetation types are distinguished with respect to site factors and ecosystem processes and can be considered as ecosystem types [23, 25]. Selected data on site factors, topsoil properties, and ecosystem productivity are presented in Table 1 . Table 2 contains aggregated data on plant-species composition of the investigated beech forest types.

The $p_{i}$ were defined by the cover percentages $D_{i}$ of species $i$ in the following:

$$
p_{i}=\frac{D_{i}}{\sum_{j=1}^{S} D_{j}}
$$

The index $i$ runs from one to total species number $S$ counted in a certain sample. Reliable diversity profiles can be obtained from measuring relative soil cover of occurring plant species on sufficiently large areas subject to the same ecological constraints.

The $N$ relevés of individual plot area $a_{j}$ corresponding to a certain ecosystem type were successively combined to composed relevés of increasing area $\sum_{j=1}^{n} a_{j}$ with $n$ running from one to $N$. For each composed relevé $(j=1, \ldots, n)$ the relative cover of different plant species and the Rényi diversity $H_{j}$ according to (1) were calculated with $q$ running from 0 to 2.0 in steps of 0.1 . In the result there are $N$ samples: the first one consisting of the $N$ original relevés of individual plot area $a_{j}$ and the last one consisting of only one composed relevé of plot area $\sum_{j=1}^{N} a_{j}$. For each $n$ with $1<n<N$ a random sample consisting of $\min \left\{\left(\begin{array}{c}N \\ n\end{array}\right), 10^{4}\right\}$ combinations of original relevés was assembled; that is, the theoretical number $\left(\begin{array}{l}N \\ n\end{array}\right)$ of possible combinations of order $n$ was restricted to a maximum of $10^{4}$. For each of the $n=1, \ldots, N$ random samples, the mean Rényi diversities $H \equiv(1 / n) \sum_{j=1}^{n} H_{j}$ were plotted versus the mean sample area $A=(1 / n) \sum_{j=1}^{n} a_{j}$. Averaging may lead to a bias if individual relevés differ in plot sizes. However, this bias can be neglected in the present calculation because relevés classified into a certain ecosystem type have identical or only slightly deviating plot sizes. In order to justify this assumption, I investigated the species distributions for all forest types considered and found highly symmetrical distribution shapes that could be well approximated by Gaussian distributions (Table 3). Hence, the calculated mean Rényi diversities $H$ correspond to the most probable values that can be expected on plots of the respective sample area.

The following nonlinear saturation equation is solution of the ordinary differential equation (6), where $C=\kappa /(\alpha$. $\left(H_{S}\right)^{1 / \kappa}$ ) and $k=1+1 / \kappa:$

$$
H=H_{S} \cdot\left[1-\left(\frac{\alpha}{A+\alpha}\right)^{\kappa}\right] .
$$

This equation was fitted to the calculated data curves versus the area $A$. The three parameters $H_{S}, \alpha, \kappa$ were estimated by a nonlinear least squares fit using a gradient-expansion algorithm (procedure CURVEFIT implemented in IDL, versus 6.3, RSI, ITT Industries, Boulder, USA).

Finally, I investigated the reliability of the modelled saturation diversities $H_{S}$ for different values of $q$ depending on the sample area. For this purpose, the total set of $N$ original samples corresponding to a particular ecosystem type was randomly divided into each of 2, 4, 6, 8, and 16 disjunctive subsets. The saturation diversities $H_{S}$ were estimated from each of the sample subsets according to the above procedure. Mean values and standard deviations of the predicted moments of saturation diversities were plotted over the sample area (Figure 3). When the predicted saturation moments remain constant with increasing sample area, they can be considered to be reliable. In this case the sample size is sufficiently large for predicting the saturation profiles with high accuracy.

\section{Results}

The nonlinear saturation model (9) very closely resembles the field data (Figures 1 and 2). The root mean squared error is generally of the order of parts per thousand of the sample mean or even smaller (Tables 3 and 4). The envelopes of error curves decline with increasing sample area, that is, with the diversities coming closer to the saturation point (Figure 2). The investigated samples sizes were sufficiently large for predicting reliable values of saturation moments from the hyperbolic model for scanning parameters $q \geq$ 0.5 as is shown for one ecosystem type in Figure 3. Similar results were obtained for all the investigated ecosystem types. In these cases a high constancy of the predicted saturation values indicates that the corresponding moments are independent on sample size. For species number $(q=$ 0 ), however, the predicted saturation value increases with increasing sample area. In this case the model proves to be inadequate and saturation cannot be expected within the considered data range.

The saturation diversity $H_{S}$ and hence the effective or apparent species number $\exp \left(H_{S}\right)$ decrease with increasing $q$ (Tables 3 and 4). The parameter $\kappa$ in (9) was found to increase with increasing $q$ (Tables 3 and 4). According to (9), the curve approaches the saturation diversity $H_{S}$ more 
rapidly with increasing $\kappa$. This means that higher moments of species distributions achieve saturation on smaller sample areas $A$. With increasing $\kappa$, the complexity parameter $k$ in (6) approaches one. This means that higher moments of species distributions are related to less cooperative processes. On the other hand, saturation of lower moments is a more complex phenomenon than saturation of higher moments (e.g., Shannon or even Simpson diversity).

Determination of the spatial scale of the corresponding processes can be obtained from measures of evenness of species distribution according to

$$
E=\frac{H}{\ln S}
$$

Equation (10) for $q=1$ corresponds to the well-known Shannon evenness. In previous work, it was shown that Shannon evenness increases up to a maximum on local scales but decreases steadily on larger areas [16]. A similar shape of evenness curves was found for all $q>0$ in this study (Figure 4$)$. The area $A_{\min }$, where evenness approaches its maximum, increases with decreasing $q$ (Figure 5). In beech forests on eutrophic loam soils (Melico-Fagetum) this area varies between $400 \mathrm{~m}^{2}$ for $q=2$ and about $4000 \mathrm{~m}^{2}$ for $q=$ 0.1 . Hence a plot size of $400 \mathrm{~m}^{2}$ would be sufficient in order to record dominant species in this forest type. Otherwise, $4000 \mathrm{~m}^{2}$ would be required for sampling most of the rare species that can be expected in this forest type.

Moments with $q>0.5$ correspond to spatial scales up to the order of squared tree height which is a natural local interaction scale within forests. Diversity profiles within this parameter range reflect species abundance distributions over a wide range from less abundant up to dominant species, only excluding occasional species. On these scales the diversity is clearly related to the following ecological constraints.

(1) Plant species diversity increases with increasing soil nutrient status and water storage capacity of soils within each of the investigated ecological series of both beech and Scots-pine forests (Tables 1, 3, and 4; Figures 6 and 7). The other ecological site factors were mostly kept constant within these ecological series.

(2) The investigated close-to-nature beech forests have a significantly lower plant-species diversity compared to the corresponding secondary Scots-pine forests on similar forest sites (Figures 8, 9, and 10).

The profiles of saturation diversity show a clear tendency to become more concave with decreasing soil quality (Figure 7). Moreover, diversity profiles of forests that are dominated by the strongly shading beech (Fagus sylvatica) in the tree layer are more concave than profiles of forests with the much more transparent canopies of Scots pine (Pinus sylvestris) (Figures 8-10). More concave diversity profiles correspond to lower evenness of plant species distributions. Summarizing the above findings, it can be confirmed that both species richness and equitability of species distribution increase with increasing availability of resources.
Both regularities are uniquely derived from the Rényi saturation diversities $H_{S}$ with the parameter $q$ continuously varying between 0.5 and 2 (a reversal of the diversity rank is observed between Melico-Fagetum and Milio-Fagetum for $q=0.5)$. The effects are most distinct for higher moments with $q \geq 1$.

\section{Discussion}

Saturation profiles of diversity and the corresponding spatial scales can be well interpreted within the framework of Grime's "mass-ratio" theory [7]. Higher moments of species distributions give more weight to dominant and subordinate species in the diversity measure. These species have immediate control on ecosystem processes such as nutrient cycling, and water balance due to their overwhelming contribution to primary production. Strongly declining diversity profiles (with increasing q) indicate that only a small part of the occurring species takes part in this immediate control. This part is decreasing with decreasing resource availability as is indicated by the increasing concavity of diversity profiles. Resource sharing between different species decreases with decreasing soil quality (Figure 7), but it increases when the dominant beech in close-to-nature forests is substituted by Scots pine in secondary forests (Figure 10). Correspondingly, natural succession in these man-made pine forests leads to a significant decrease in plant species diversity due to the growing dominance of strongly shading beech trees. Total above-ground net productivity in close-to-nature beech forests is significantly higher than in secondary pine forests due to the contribution of woody biomass (Table 1). Hence there is no simple relationship between plant species diversity and ecosystem productivity.

The more weight is given to dominant and subordinate species, the smaller is the area required to observe the corresponding diversity patterns. The minimum area to cover the vegetation patterns that determine different moments of the distribution can be estimated from the peak of the evenness curve according to (10). It turns out that area sizes about squared tree height do correspond to moments of order $q>$ 0.5 in North-Central European forests (Figure 5). This result is compatible with the fact that trees, in the main, control primary production, nutrient cycling and water balance in forests.

About twenty relevés of about $500 \mathrm{~m}^{2}$ plot size each are sufficient to predict reliable saturation diversities for forest ecosystem types with $q \geq 0.5$ from a hyperbolic model. This corresponds to a total sample area of about one to few hectares. The corresponding species distributions represent the vegetation potentials of the sites that are subject to similar ecological constraints.

The more weight is given to rare species, the larger is the sample area where saturation of diversity is approached. The complexity of the processes that control the saturation of species diversity increases when greater weight is given to rare species. The lower moments (in particular species number) are more strongly influenced by species delivery from the surroundings, that is, by long-range interactions 
like species migration and dispersal. Grime emphasizes the importance of occasional or transient species for ecosystem function and sustainability [7]. These low-abundant species originate from the seed rain and seed banks and provide the potential for developing new dominants and subordinates following temporal perturbations or systematic shifts of site conditions as can be expected, for example, in the outcome of climate change. The effects of these species become apparent on longer time scales.

There was no reliable saturation confirmed for species number $(q=0)$. For $q$ close to zero, the diversity is strongly influenced by the stochastic presence of occasional species. The accumulated samples were taken from different geographic locations and may be embedded in completely different landscape surroundings with different species delivery. A saturation of species number cannot be expected under these circumstances.

Ricotta and Anand [26, 27] developed a measure of structural complexity for plant communities based on the information-theoretical framework of Juhász-Nagy [28, 29]. This measure quantifies the amount of spatial correlation between the species in plant assemblages as a function of scale. It shows a peaked behaviour with at least one maximum at intermediate scales. The approach is based on information entropies of the Shannon type. Hence it would be interesting to compare the spatial scales obtained by these authors with the corresponding values obtained for $q=1.0$ by the more simple approach presented in this paper.

In this paper I restricted myself to the discussion of the hyperbolic saturation behaviour of diversity curves. Hyperbolic saturation of diversity with increasing area can be expected for large sample areas within a particular biogeographic region (limited species pool) and with homogeneous or repeating environments. On small areas, along changing environments or changing bio-geographic regions with a changing species pool, a law with exponents can be expected not only for species richness (classical SAR) but also for Shannon and Simpson diversity [30].

\section{Concluding Remarks}

The hyperbolic saturation model applied in this study is not only a tool for data fitting but also a theoretical model for a certain type of saturation behaviour. This model can improve our understanding of the relationships between biodiversity, spatial scale, and ecosystem functioning when applied to the study of diversity profiles.

Shannon or Simpson diversities are well suited to describe vegetation patterns that are strongly related to ecosystem processes like primary production, nutrient cycling, and water balance. The latter processes are mainly controlled by species of high and medium abundance. Low values of these diversity indices may indicate a strong limitation of resources but also a high adaptation of few species to the site conditions. These ecosystem processes are tightly related to the local site conditions and to the dimension of dominant species, which determine the sample area required for analysing the corresponding vegetation patterns. This minimum area corresponds to the point of maximal evenness that can be obtained for a certain ecosystem type according to the method developed here.

Low moments of the diversity profiles that give more weight to rare species have a great importance for the adaptability of ecosystems. The corresponding vegetation patterns can be observed on rather large spatial scales and are the result of a complex networking of many processes as indicated by our mathematical analysis. Despite their great importance for ecosystem sustainability, these complex processes on landscape scales are poorly understood up to now.

\section{Acknowledgments}

The work was funded by the German Federal Ministry for Education and Research (BMBF) under contract no. $0330562 \mathrm{H}$. The author is responsible for the content of the publication. The author is indebted to Gerhard Hofmann, Ulf Pommer, Sybille, and Michael Wehner who provided major contributions to the development of the investigated ecological database. Furthermore, the author is grateful to Carlo Ricotta and three anonymous referees who gave valuable hints on earlier versions of this paper.

\section{References}

[1] E. C. Pielou, Ecological Diversity, Wiley, New York, NY, USA, 1975.

[2] C. Ricotta, "Through the jungle of biological diversity," Acta Biotheoretica, vol. 53, no. 1, pp. 29-38, 2005.

[3] M. O. Hill, "Diversity and evenness: a unifying notation and its consequences," Ecology, vol. 54, pp. 427-432, 1973.

[4] B. Tóthmérész, "Comparison of different methods for diversity ordering," Journal of Vegetation Science, vol. 6, no. 2, pp. 283-290, 1995.

[5] D. A. Walker, et al., "Developing a 'richness-free' statistic for measuring ecosystem diversity in landscape decision support," in Science and Management of Protected Areas, Victoria, Canada, 2003.

[6] R. S. Mendes, L. R. Evangelista, S. M. Thomaz, A. A. Agostinho, and L. C. Gomes, "A unified index to measure ecological diversity and species rarity," Ecography, vol. 31, no. 4, pp. 450-456, 2008.

[23] M. Jenssen, "Im Gebiet verbreitete Typen von Wald- und Forstökosystemen als ökologische Elementareinheiten des Waldes mit Grundlageninformationen für Waldbewirtschaftung und Waldstabilität," in Ökologie und Vegetation der Wälder Nordostdeutschlands, S. Anders, et al., Ed., pp. 157177, Dr. Kessel, Oberwinter, Germany, 2002.

[7] J. P. Grime, "Benefits of plant diversity to ecosystems: immediate, filter and founder effects," Journal of Ecology, vol. 86, no. 6, pp. 902-910, 1998.

[8] A. Rényi, "On measures of entropy and information," in Proceedings of the 4th Berkeley Symposium on Mathematical Statistics and Probability, University of California Press, Berkeley, Calif, USA, 1961.

[9] A. I. Khinchin, Mathematical Foundations of Information Theory, Dover, New York, NY, USA, 1957.

[10] A. Rényi, Probability Theory, North-Holland, Amsterdam, The Netherlands, 1970. 
[11] C. E. Shannon, "A mathematical theory of communication," Bell System Technical Journal, vol. 27, pp. 370-423, 623-656, 1948.

[12] C. Beck and F. Schlögl, Thermodynamics of Chaotic Systems: An Introduction, Cambridge University Press, Cambridge, UK, 1993.

[13] E. Simpson, "Management of diversity," Nature, vol. 163, p. 688, 1949.

[14] T. O. Kvalseth, "Note on biological diversity, evenness, and homogeneity measures," Oikos, vol. 62, no. 1, pp. 123-127, 1991.

[15] R. K. Peet, "The measurement of species diversity," Annual Review of Ecology and Systematics, vol. 5, pp. 285-307, 1974.

[16] M. Jenssen, "Ecological potentials of biodiversity modelled from information entropies: plant species diversity of NorthCentral European forests as an example," Ecological Informatics, vol. 2, no. 4, pp. 328-336, 2007.

[17] W. Mende, "The evolon model and its applications to natural processes," in Approach to Cooperation and Competition in Dynamic Systems, W. Ebeling and M. Peschel, Eds., pp. 261271, Akademie, Berlin, Germany, 1985.

[18] M. Peschel and W. Mende, The Predator-Prey Model: Do We Live in a Volterra World? Akademie, Berlin, Germany, 1986.

[19] W. Mende and K.-F. Albrecht, "Electric energy production as an evolutionary process," in Evolution and Optimization, $\mathrm{H}$. Mühlenbein and H.-P. Schwefel, Eds., pp. 177-189, Akademie, Berlin, Germany, 1990.

[20] W. Mende and K.-F. Albrecht, "Description and interpretation of the growth of spruces by means of the Evolon-model," Forstwissenschaftliches Centralblatt, vol. 120, no. 2, pp. 53-67, 2001.

[21] U. Bohn and R. Neuhäusl, Map of the Natural Vegetation of Europe, Landwirtschaftsverlag, Münster, Germany, 2003.

[22] G. Hofmann and U. Pommer, Potentielle Natürliche Vegetation von Brandenburg und Berlin, Eberswalder Forstliche Schriftenreihe, XXIV, Potsdam, Germany, 2003.

[24] G. Hofmann, "Neue Wege der Vegetationsforschung," Archiv für Forstwesen, vol. 18, pp. 225-224, 1969.

[25] M. Jenssen, "An empirically based approach to selforganisation in forest ecosystems," in Integrative Systems Approaches to Natural and Social Dynamics. Systems Science 2000, M. Matthies, H. Malchow, and J. Kriz, Eds., Springer, Berlin, Germany, 2001.

[26] C. Ricotta and M. Anand, "Spatial scaling of structural complexity in plant communities," International Journal of Ecology and Environmental Sciences, vol. 30, no. 2, pp. 93-99, 2004.

[27] C. Ricotta and M. Anand, "Spatial complexity of ecological communities: bridging the gap between probabilistic and nonprobabilistic uncertainty measures," Ecological Modelling, vol. 197, no. 1-2, pp. 59-66, 2006.

[28] P. Juhász-Nagy, "Spatial dependence of plant populationspart 1: equivalence analysis (an outline for a new model)," Acta Botanica Academiae Scientiarum Hungaricae, vol. 22, pp. 6178, 1976.

[29] P. Juhász-Nagy, "Spatial dependence of plant populationspart 2: a family of new models," Acta Botanica Academiae Scientiarum Hungaricae, vol. 30, pp. 363-402, 1984.

[30] K. Ma, M. Anand, and B. Fu, "Do generalized scaling laws exist for species abundance distribution in mountains?" Oikos, vol. 115 , no. 1, pp. 81-88, 2006. 

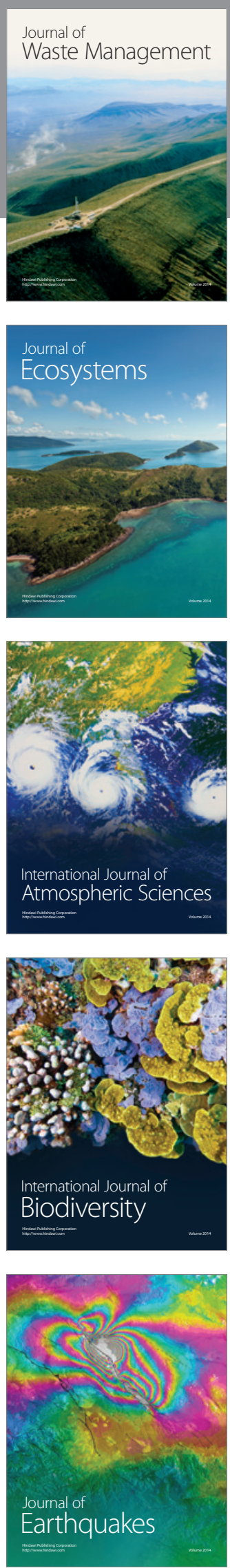
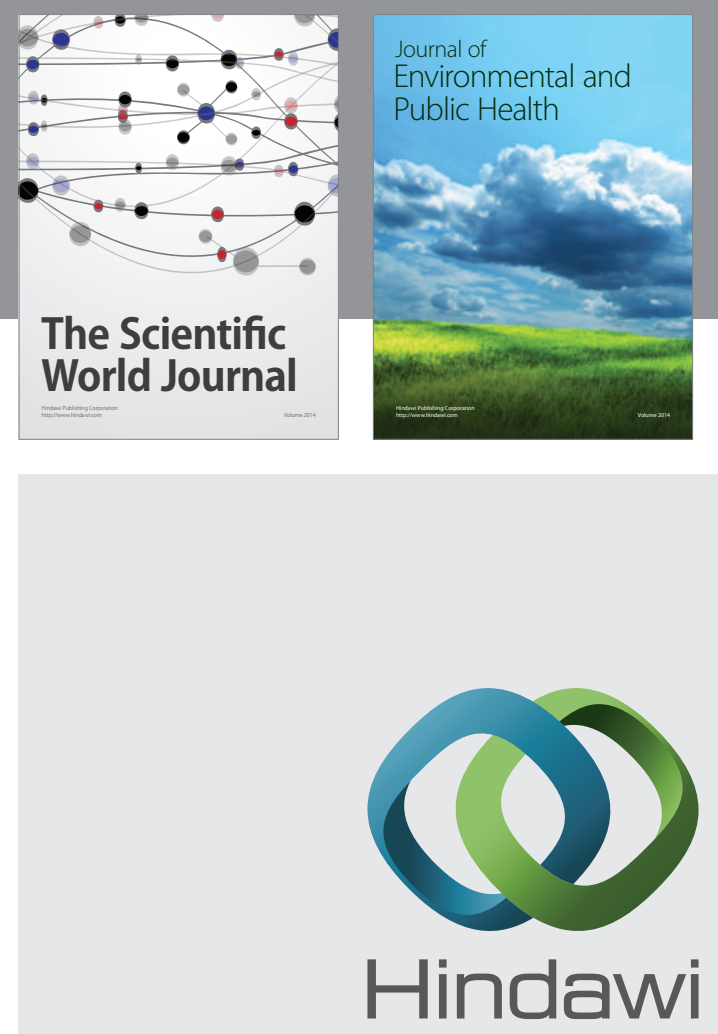

Submit your manuscripts at

http://www.hindawi.com
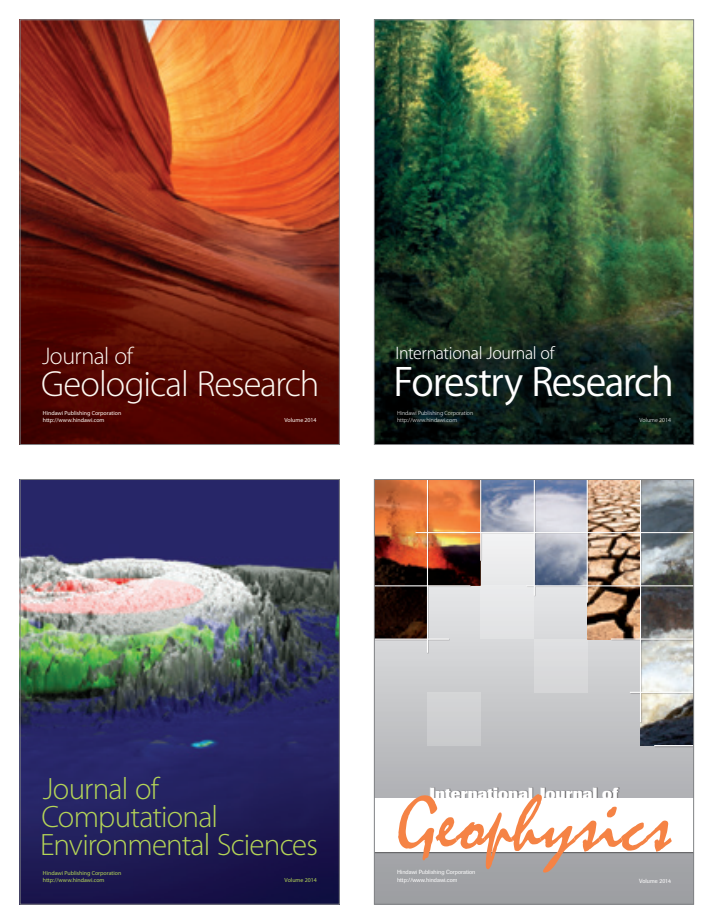
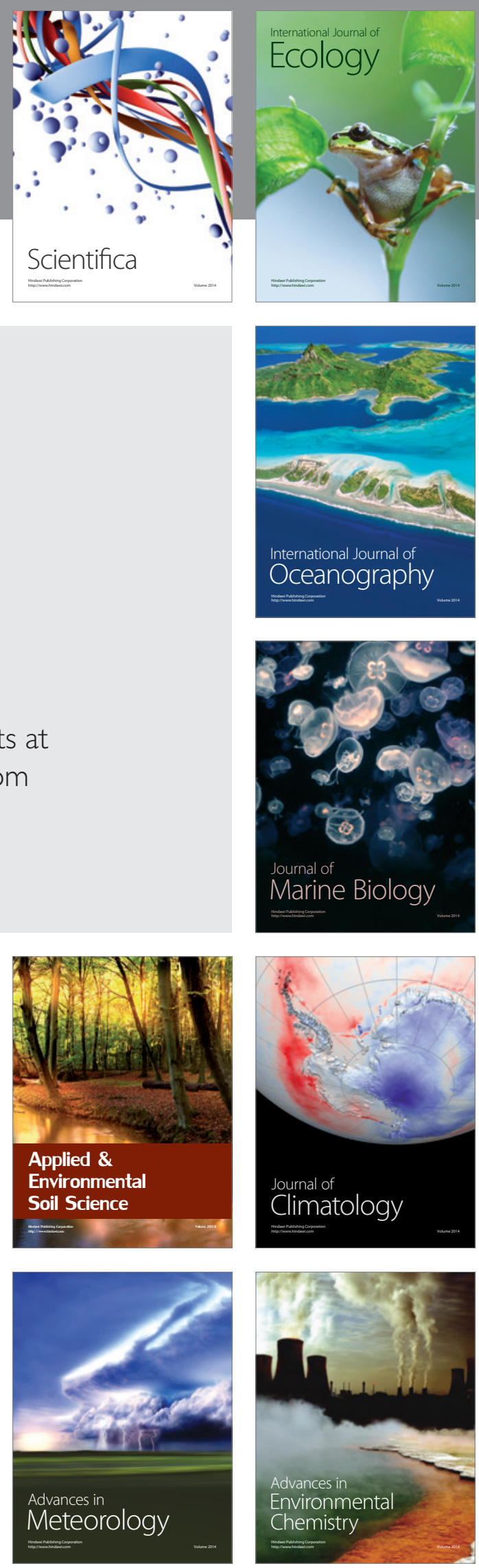